Siti Munawaroh dan Sri Widyastuti : Penjerapan Logam Besi (Fe) Menggunakan Adsorben Cangkang Kerang Darah (Anadara Granosa Linn)

\title{
PENJERAPAN LOGAM BESI (Fe) MENGGUNAKAN ADSORBEN CANGKANG KERANG DARAH (Anadara granosa Linn)
}

\author{
Siti Munawaroh ${ }^{1)}$ dan Sri Widyastuti ${ }^{1)}$ \\ 1) Program Studi Teknik Lingkungan, Fakultas Teknik Sipil dam Perencanaan \\ Universitas PGRI Adi Buana Surabaya \\ Email: sriwidyastuti@unipasby.ac.id
}

\begin{abstract}
Abstrak
Air yang tercemar perlu penanganan yang baik. Salah satu pencemaran air yang terjadi diakibatkan karena mengandung logam berat. Salah satu logam berat yang dapat mencemari air adalah logam besi. Cangkang kerang darah yang melimpah masih kurang penangannya dalam pengelolaan atau pemanfaatannya. Penelitian ini bertujuan untuk memanfaatkan cangkang kerang darah sebagai adsorben untuk pengelolaan air yang mengandung logam besi. Selain itu, manfaat dari penelitian ini adalah dapat memberikan penanganan pengolahan air yang mengandung ion Fe dengan alternatif penggunaan adsorben dari alam. Metode dalam penelitian ini yaitu melakukan pengadukan antara adsorben dari cangkang kerang darah sebanyak 2 gram dengan $500 \mathrm{ml}$ larutan logam besi sebesar 20 ppm. Waktu pengadukan yaitu 90 menit, 120 menit, dan 150 menit. Cangkang kerang darah di furnace terlebih dahulu untuk mendapatkan luas permukaan yang maksimal dalam penjerapan logam berat. Suhu yang digunakan yaitu sebesar $500^{\circ} \mathrm{C}$ selama 4 jam untuk menghasilkan luas permukaan yang baik. Hasil dari penelitian ini menunjukkan penjerapan paling efektif ketika waktu pengadukan selama 90 menit dengan efisiensi penyisihan sebesar 99,79\%, dengan kadar besi akhir pada larutan sebesar 0,041 ppm.
\end{abstract}

Kata Kunci: serbuk cangkang kerang darah, adsorben, waktu pengadukan, kadar besi

\begin{abstract}
Polluted water need good handling. One of the water pollution that it contains heavy metals. One of the heavy metal is iron metal. The blood clam shells are less handling in management or utilization. This research for utilize the blood clam shell as an adsorbent to manage the water contamination iron metal. The benefit of this research is we can to know the water treatment contamination iron metal with adsorbent from nature. A method in this research is to do stirring between 2 grams of adsorbent with $500 \mathrm{ml}$ of $20 \mathrm{ppm}$ iron metal solution. Time stirring that 90 minutes, 120 minutes, and 150 minutes. The blood clam shell in furnace to get maximum surface area in the absorption of heavy metal. Temperature used $500^{\circ} \mathrm{C}$ for 4 hours to a good produce surface area. The result of this research is the most effective absorption when the time stirring that 90 minutes with removal efficiency is 99,79\%, the last iron content in the solution is 0,041 ppm.
\end{abstract}

Keyword: blood clam shells powder, adsorbent, time stirring, iron content 


\section{PENDAHULUAN}

Air merupakan kehidupan untuk makhluk hidup terutama manusia. Air yang tercemar perlu penanganan khusus dalam pengelolaannya agar tidak mencemari lingkungan. Salah satu teknologi yang dapat digunakan dalam pengolahan air yaitu dengan metode adsorpsi. Adsorpsi merupakan fenomena fisika dimana partikel - partikel bahan yang diadsorpsi tertarik pada permukaan bidang padat yang bertindak sebagai adsorben (Pahlevi, 2009). Adsorben yang saat ini sebagai tantangan yaitu adsorben yang ekonomis dan efisien untuk meminimalisir biaya operasi terutama untuk negara berkembang (Priadi dkk, 2014). Ketertarikan akan sumber bahan baku yang berasal dari limbah semakin meningkat. Misalnya cangkang hewan laut yang dapat digunakan sebagai bahan baku yang dapat dimanfaatkan kembali. Di negara maju seperti Jepang hewan laut seperti tiram dimanfaatkan kembali sebagai bahan baku pembuatan adsorben pada cangkangnya karena cangkang tiram terdapat sumber kalsium (Hiroaki, 2012).

Saat ini sedang dikembangkan penggunaan adsorben alternatif yang berasal dari alam. Limbah cangkang kerang darah telah menarik perhatian untuk digunakan sebagai adsorben alam. Cangkang kerang darah memiliki kandungan $\mathrm{CaCO}_{3}$. Kalsium karbonat merupakan bahan yang sesuai dalam penghilangan senyawa toksik seperti limbah logam berat. $\mathrm{CaCO}_{3}$ secara fisik mempunyai pori - pori yang memiliki kemampuan mengadsorpsi atau menyerap zat - zat lain kedalam pori - pori permukaannya (Anugerah dan Iriany, 2015). Cangkang kerang juga aman karena tidak mengandung logam berat (Widyastuti dan Wiyarno, 2016).

Penelitian mengenai penggunaan kalsium karbonat $\left(\mathrm{CaCO}_{3}\right)$ sebagai adsorben alternatif yang berasal dari alam, seperti dari limbah cangkang telur dapat mengadsorbsi ion $\mathrm{Fe}$ sebesar 99,82\% (Asip dkk, 2008). Cangkang kerang darah dapat mengadsorbsi zat organik pada air gambut sebesar 99,86\% (Ermal dkk, 2016). Cangkang kerang bulu dapat menjerap Cd sebesar 99,38\% dan $\mathrm{Pb}$ sebesar 99,98\%
(Anugerah dan Iriany, 2015). Cangkang kerang darah dapat menurunkan kadar $\mathrm{Cu}^{2+}$ sebesar 96\% selama 90 menit (Hapsari, 2016).

Dalam penelitian ini pencemaran air dapat berupa terpaparnya air dengan senyawa logam berat. Maka perlu penanganan lebih lanjut agar air yang mengandung logam berat tidak mencemari lingkungan. Salah satu logam berat yang dapat mencemari adalah ion Fe. Munculnya ion $\mathrm{Fe}$ pada perairan atau kandungan di dalam air diakibatkan oleh aktivitas manusia. Aktivitas manusia ini bisa berupa dari kegiatan industri maupun kegiatan rumah tangga. Perlu penanganan lebih lanjut untuk pengelolaan air yang mengandung logam berat besi. Penelitian dilakukan untuk mengetahui efisiensi kadar besi setelah dilakukan penjerapan oleh serbuk cangkang kerang darah terhadap ion Fe. Adsorben dari serbuk cangkang kerang darah diharapkan dapat menurunkan kadar $\mathrm{Fe}$ pada larutan atau perairan yang mengandung logam besi.

\section{METODE}

\section{Rancangan Penelitian}

Penelitian ini melakukan pemeriksaan kadar Fe pada larutan setelah pengadukan dengan adsorben. Waktu pengadukan dengan adsorben adalah 90 menit, 120 menit, dan 150 menit. Tempat penelitian di Laboratorium Teknik Lingkungan Unipa Surabaya dan UPT Laboratorium DLH Provinsi Jawa Timur untuk analisis sampel. Penelitian ini dilakukan untuk mengetahui waktu pengadukan yang paling efektif dalam mereduksi logam besi (Fe) pada larutan yang mengandung logam besi $(\mathrm{Fe})$. Rancangan percobaan yang digunakan dalam penelitian ini adalah waktu pengadukan larutan dengan adsorben cangkang kerang selama 90 menit, 120 menit, dan 150 menit serta dilakukan pengulangan sebanyak 3 kali.

\section{Populasi dan Penentuan Sampel Populasi}

Populasi dalam penelitian ini adalah larutan logam besi $(\mathrm{Fe})$ 


\section{Sampel}

Sampel dalam penelitian ini adalah sampel buatan larutan logam besi $(\mathrm{Fe})$

\section{Alat dan Bahan}

Alat

Alat yang digunakan dalam penelitian ini sebagai berikut: flokulator, neraca analitik, mortar, cawan porselin, beaker glass, gelas ukur, kertas saring, pipet tetes, ayakan 200 mesh, furnace, desikator, dan Spektrofotometer Serapan Atom (SSA).

\section{Bahan}

Bahan yang digunakan dalam penelitian ini sebagai berikut: serbuk cangkang kerang darah, aquades, dan larutan logam besi $(\mathrm{Fe})$ $20 \mathrm{ppm}$.

\section{Metode Pengumpulan Data}

Pengumpulan data pada penelitian ini yaitu, persiapan adsorben: pencucian cangkang kerang darah lalu dijemur, penghalusan cangkang kerang darah lalu diayak dengan ayakan 200 mesh, panaskan serbuk cangkang kerang darah di dalam furnace dengan suhu $500^{\circ} \mathrm{C}$ selama 4 jam, setelah selesai pemanasan letakkan pada desikator. Persiapan sampel buatan larutan besi 20 ppm. Pengadukan sampel buatan dengan adsorben: pemberian adsorben cangkang kerang darah sebanyak 2 gram ke dalam $500 \mathrm{ml}$ larutan sampel buatan dalam masing-masing beaker glass, melakukan pengadukan sesuai waktu pengadukan yang telah ditentukan selama 90 menit, 120 menit dan 150 menit dengan kecepatan pengadukan sebesar $200 \mathrm{rpm}$. Pengiriman pemeriksaan sampel ke UPT Laboratorium DLH Provinsi Jawa Timur.

\section{Metode Analisis Data}

Metode analisis data pada penelitian ini secara deskriptif dan disajikan dalam bentuk grafik, yaitu hasil dari pemeriksaan laboratorium yang dilakukan di UPT Laboratorium DLH Provinsi Jawa Timur untuk mengetahui waktu pengadukan dalam penjerapan kadar $\mathrm{Fe}$ pada larutan logam besi $(\mathrm{Fe})$ dengan adsorben cangkang kerang darah (Anadara granosa Linn).

\section{HASIL DAN PEMBAHASAN}

Berdasarkan data hasil pengujian kadar Fe oleh UPT Laboratorium DLH Provinsi Jawa Timur bahwa adsorben cangkang kerang darah dapat menurunkan kadar Fe pada larutan logam besi (Fe) pada air. Namun, persentase efisiensi penyisihan kadar besi pada larutan logam besi menurun seiring dengan lama waktu pengadukan disajikan pada Gambar 1.

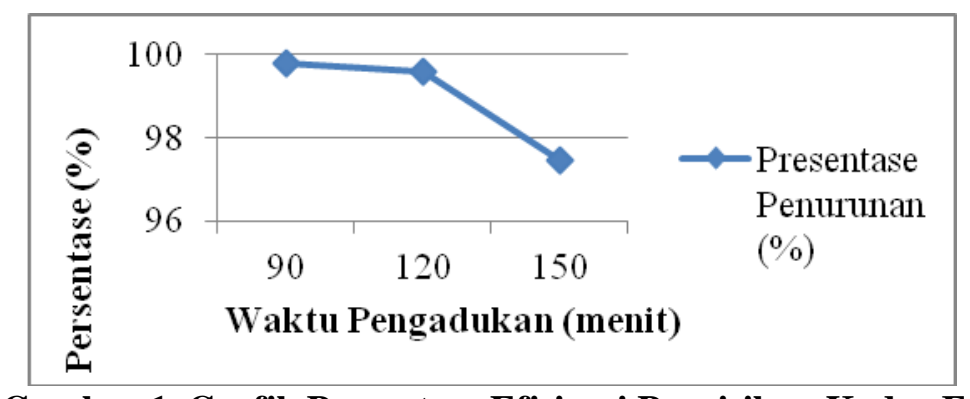

Gambar 1. Grafik Persentase Efisiensi Penyisihan Kadar Fe

Faktor penurunan penjerapan akibat lama waktu pengadukan bisa diakibatkan karena faktor jenuh pada adsorban. Pori - pori adsorben dapat menjadi jenuh sehingga tidak dapat menjerap lagi logam berat (Herlandien, 2013) dan pada saat kondisi tertentu efisiensi penjerapan akan konstan karena telah terjadi kejenuhan pada adsorben
(Nor,2013). Kemampuan $\mathrm{CaCO}_{3}$ menurun ketika waktu pengadukan semakin lama. Luas permukaan pada adsorban cangkang kerang darah sudah jenuh sehingga mengakibatkan adsorban tidak efektif lagi untuk digunakan. Variasi waktu pengadukan antara adsorban cangkang kerang darah dengan sampel buatan larutan logam besi dari 
90 menit, 120 menit dan 150 menit penurunan penjerapan terjadi karena ketika kondisi waktu pengadukan selama 90 menit efisiensi yang terjadi hampir $100 \%$. Sehingga waktu pengadukan selama 90 menit dianggap paling efektif.

Kadar $\mathrm{Fe}$ pada larutan yang terjerap oleh serbuk cangkang kerang darah (Anadara granosa Linn) pada waktu pengadukan selama 90 menit mengalami penurunan sebesar $99,79 \%$. Kondisi tersebut didukung oleh serbuk cangkang kerang darah dengan ukuran 200 mesh sebelum perlakuan terlebih dahulu melalui tahap pem-furnace an dengan suhu $500^{\circ} \mathrm{C}$ selama 4 jam yang mengakibatkan luas permukaan yang dihasilkan cukup mampu menjerap logam besi yang terkandung di dalam air. Selain itu kecepatan untuk pengadukan sebesar $200 \mathrm{rpm}$. Kalsium karbonat $\left(\mathrm{CaCO}_{3}\right)$ merupakan bahan yang sesuai dalam penghilangan senyawa toksik seperti logam berat yang terkandung di dalam air. Kalsium karbonat secara fisik mempunyai pori pori yang memiliki kemampuan mengadsorpsi zat - zat lain ke dalam pori - pori permukaannya, sehingga mampu untuk mengurangi kadar logam ion $\mathrm{Cu}^{2+}$ di dalam air (Anugerah dan Iriany, 2015).

Pada penelitian sebelumnya serbuk cangkang kerang bulu bisa mengadsorb kadmium (Cd) sebesar 99,38\% dengan konsentrasi awal larutan sebesar $60 \mathrm{ppm}$ dan timbal $(\mathrm{Pb})$ sebesar 99,98\% dengan konsentrasi awal larutan sebesar 60 ppm, ukuran serbuk cangkang kerang bulu sebesar 140 mesh, cangkang kerang bulu di furnace terlebih dahulu dengan suhu $500^{\circ} \mathrm{C}$ selama 4 jam, kecepatan pengadukan larutan sebesar $200 \mathrm{rpm}$ (Anugerah dan Iriany, 2015). Cangkang kerang dijadikan koagulan untuk menurunkan pecemaran air (Tiandho dkk, 2018). Penelitian tentang adsorbsi dari cangkang telur bisa menurunkan kadar besi pada larutan sebesar 99,82\% dengan waktu pengadukan selama 60 menit untuk ukuran 1000 mesh dan dengan kecepatan pengadukan $300 \mathrm{rpm}$, sedangkan untuk waktu kontak atau lama pengadukan selama 120 menit untuk ukuran 250 mesh bisa menurunkan kadar besi sebesar 98,41\%. Pada waktu pengadukan selama 180 menit adsorben mengalami kejenuhan, tingkat efisiensi penjerapan menurun sebesar $97,57 \%$ untuk ukuran adsorben 250 mesh (Asip dkk, 2008).

Cangkang kerang darah yang berupa serbuk dapat menjerap logam besi $(\mathrm{Fe})$ pada air. Efisiensi penyisihan yang terbaik pada penelitian ini ketika waktu pengadukan selama 90 menit sebesar 99,79\%. Pada saat waktu kontak 120 menit adsorben mengalami kejenuhan yang mengakibatkan penjerapan logam besi berkurang. Pengelupasan adsorbat pada waktu pengadukan di atas 90 menit terjadi karena adsorben telah jenuh sehingga kadar logam besi kembali ke sampel buatan larutan logam besi. Alternatif pengolahan air yang mengandung logam besi bisa menggunakan adsorben yang ramah lingkungan dan terhitung ekonomis yaitu adsorben dari cangkang kerang darah.

\section{KESIMPULAN}

Hasil dari penelitian ini adalah efisiensi penyisihan logam besi $(\mathrm{Fe})$ sebesar $99,79 \%$, dengan kadar besi akhir pada larutan sebesar 0,041 ppm. Waktu pengadukan yang optimum selama 90 menit untuk ukuran cangkang kerang darah 200 mesh dengan mem-furnace pada suhu $500^{\circ} \mathrm{C}$ selama 4 jam dan dengan kecepatan pengadukan sebesar $200 \mathrm{rpm}$.

\section{UCAPAN TERIMA KASIH}

Ucapan terima kasih disampaikan kepada kepala Laboratorium Teknik Lingkungan yang telah banyak membantu dalam penelitian dan menyediakan alat dan bahan penelitian serta ke UPT Laboratorium DLH Provinsi Jawa Timur. 
Siti Munawaroh dan Sri Widyastuti : Penjerapan Logam Besi (Fe) Menggunakan Adsorben Cangkang Kerang Darah (Anadara Granosa Linn)

\section{DAFTAR PUSTAKA}

Anugerah, S.A. dan Iriany. 2015. Pemanfaatan Limbah Cangkang Kerang Bulu sebagai Adsorben untuk Menjerap Logam Kadmium (II) dan Timbal (II). Jurnal Teknik Kimia USU. Vol 4(3) : 40-45.

Asip, F., Mardhiah, R., dan Husna. 2008. Uji Efektifitas Cangkang Telur dalam Mengadsorbsi Ion Fe dengan Proses Batch. Jurnal Teknik Kimia. Vol 15(2) : 2226.

Ermal, D.A.S., Elystia, S., dan Aziz, Y. 2016. Pemanfaatan Precipitated Calcium Carbonate (PCC) dari Limbah Cangkang Kerang Darah (Anadara granosa) sebagai Adsorben Pengolahan Air Gambut. Jurnal Mahasiswa Fakultas Teknik. Vol 3(2) : 1-11.

Hapsari, A.R. 2016. Penurunan Kadar Ion Tembaga $\left(\mathrm{Cu}^{2+}\right)$ dalam Air Menggunakan Serbuk Cangkang Kerang Darah (Anadara granosa). Skripsi. Fakultas Ilmu Keperawatan dan Kesehatan. Universitas Muhammadiyah Semarang. Semarang.

Herlandien, Y.L. 2013. Pemanfaatan Arang Aktif sebagai Adsorben Logam Berat dalam Air Lindi di TPA Pakusari Jember. Fakultas MIPA. Universitas Jember. Jember.

Hiroaki, Onada dan Hironari Nakanishi. 2012. Preparation of Calcium Phospate With Oyster Shell. Journal Scientific Research. 3 : 71-74.

Nor, F. 2013. Sintesis Biomassa Bulu Ayam Teraktivasi $\mathrm{NaOH} / \mathrm{Na}_{2} \mathrm{SO}_{3}$ sebagai Penurun Kadar Logam Tembaga dalam Larutan. Skripsi. Fakultas MIPA. Universitas Negeri Semarang. Semarang.

Pahlevi, M.Z. 2009. Analisi Kadar Besi (Fe) dan Mangan (Mn) dari Air Gambut dengan Penambahan Tulang Ayam. Tesis. Universitas Sumateta Utara. Medan.

Priadi, C.R., Anita, Sari., P.N., dan Moersidi, S.S. 2014. Adsorpsi Logam Seng dan Timbal pada Limbah Cair Industri Keramik oleh Limbah Tanah Liat. Reaktor. Jurnal Teknik Lingkungan. Vol 15(1) : 10-19.

Tiandho, Y., Aldila, H., Mustari, Megio, and Afriani, F. 2018. Utilization of Wasted Cockle Shell as a Natural Coagulant and a Neutralizer of Polluted Water in Bangka Belitung Islands, Indonesia. Journal of Physics. Conf. Series 1013 012181.

Widyastuti, Sri dan Wiyarno, Y. 2016. Heavy Metal Content on Micro Calsium of Blood Clam Shell (Anadara Granosa Linn) (pp. 159 - 163). Universitas Airlangga: Faculty of Public Health. 